\title{
Non-Destructive testing based method for crack detection in beams
}

\author{
Akash Vardhan ${ }^{\mathrm{a}^{*}}$ and Amanpreet Singh ${ }^{\mathrm{b}}$
}

${ }^{a}$ Department of Production Engineering, Jadavpur University, Kolkata, India ${ }^{b}$ Department of Mechanical Engineering, Indian School of Mines, Dhanbad, India

\begin{tabular}{|c|c|}
\hline $\begin{array}{l}\text { ART I C LE I NFO } \\
\end{array}$ & A B S T R A C T \\
\hline $\begin{array}{l}\text { Article history: } \\
\text { Received January 20, } 2014 \\
\text { Received in Revised form } \\
\text { April, 10, } 2014 \\
\text { Accepted } 15 \text { April } 2014 \\
\text { Available online } \\
17 \text { April } 2014 \\
\text { Keywords: } \\
\text { Non-destructive testing } \\
\text { Modal frequencies } \\
\text { Stiffness } \\
\text { Crack location } \\
\text { Crack size } \\
\text { Axial vibration }\end{array}$ & $\begin{array}{l}\text { Beams are the constituent elements of several machine parts and sophisticated } \\
\text { structures. In this paper, efforts are made to develop suitable methods that can serve } \\
\text { as the basis to detect crack location and to crack size from measured axial vibration } \\
\text { data. This method is used to address the inverse problem of assessing the crack } \\
\text { location and crack size in various beam structure. The method is based on } \\
\text { measurement of axial natural frequencies, which are global parameter and can be } \\
\text { easily measured from any point on the structure. In theoretical analysis, the } \\
\text { relationship between the natural frequencies, crack location, and crack size has been } \\
\text { developed. For identification of crack location and crack size, it was shown that data } \\
\text { on the variation of the first two natural frequencies is sufficient. The experimental } \\
\text { analysis is done to verify the practical applicability of the theoretical method } \\
\text { developed. }\end{array}$ \\
\hline
\end{tabular}

\section{Introduction}

Mostly modal frequencies are used for monitoring the crack because modal frequencies are properties of the whole component. The natural frequency of the component decreases as a result of crack. Many methods have been developed to detect and locate the crack by measuring the change in the natural frequencies of the component due to crack. One of the earliest works regarding the crack detection using vibration is given by Adams and Cawley (1978). They consider the crack at the fixed end of the beam. A theoretical model based on the receptance technique for analysis of structures that can be treated as one-dimensional is presented. The crack is modelled as a massless liner spring. The natural modes of cantilever beams with symmetric cracks were investigated by Christides and Barr

* Corresponding author. Tel: +91-8294629913

E-mail addresses: vardhanakash16@gmail.com (A. Vardhan) 
(1984) who used a two-term Rayleigh-Ritz solution to obtain the variation in fundamental frequency of beams with a mid-span crack.

Ostachowicz and Krawczuk (1991) analysed the effect of two cracks on fundamental frequency of cantilever beam. Two types of cracks are considered: double-sided, which occurs in the case of cyclic loading, and single-sided, which occurs as a result of fluctuating loadings. Kam and Lee (1991) have proposed a method for identifying a crack in a structure using modal test data. Static deflection analysis of the structure with and without crack is performed and a strain energy equilibrium equation is constructed for determining the size of the crack. Rizos and Aspragathos (1990) suggested a method for using measured amplitudes at two points of a cantilever beam vibrating at one of its natural modes to identify crack location and depth. Narkis (1994) has derived a close relationship between crack location and eigenfrequency changes for cantilever beam in transverse vibration and longitudinal vibration.

Stubbs and Broome (1990) suggest the use of sensitivity equations resulting from a perturbation analysis of the equation of motion, to detect the location of structural differences in continuous systems. They used both bending and axial natural frequency for this identification process. An integrated approach for detection of multiple discrete cracks using modal parameters has been put forward by Liang et al. (1992). The same approach has been extended to multiple crack assessment in beam with different boundary conditions like simply supported beam, cantilever beam, and continuous beam etc. by Liang and Hu (1993). Ishak et al. (2000) conducted strip element method calculations and experimental results to identify the crack location. In the theoretical analysis, the beam is divided into domains and a harmonic load is applied on its surface. In the theoretical analysis, the beam is divided into domains and a harmonic load is applied on its surface. Expressions for bending vibrations of an Euler-Bernoulli beam were determined by Matveev and Bovsunovsky (2002). They studied the effects of the ratio of crack location to the length of the beam and also the ratio of the depth of the crack to the height of the beam. They investigated the variation of the natural frequency of the beam.

Ren and Roeck (2002) experimentally developed a methodology of structural damage identification through changes in the dynamic characteristics. They used concrete beams stiffness for damage assessment and the proposed methodology relied on the fact that damage leads to changes in the dynamic properties of the structure such as natural frequencies and mode shapes. Zheng and Kessissoglou (2004) takes rotational spring as dominant influence of the bending moment for the opening type of crack into consideration. The excitation of the system is characterized by the simultaneous interaction of the static and dynamic harmonic loads. Simulated measured data in some locations of the structure were obtained by the numeric solution of the nonlinear analytical model of the structure with a crack. The finite element method was used to obtain the natural frequencies and mode shapes of a cracked beam. They obtained the flexibility matrix for a cracked beam by adding the crack flexibility to the flexibility matrix of the intact beam element as an overall additional flexibility matrix instead of adding it as a local flexibility matrix. Douka and Hadjileontiadis (2005) considered a simple periodic function to model the time-varying stiffness of a beam. However, this model is limited to the fundamental mode so that the equation of motion for the beam must be solved.

Loya and Rubio (2006) studied the lateral vibration of a cracked Timoshenko beam. The beam was simulated as two beams connected by extensional and rotational massless springs at the crack location. The beam natural frequencies were found by direct solution for the differential equations of 
motion. Also, a perturbation solution to calculate the system's natural frequencies was derived. A closed form solution was obtained for only a simply supported beam. Al-Said (2008) developed a crack identification algorithm based on a mathematical model to identify crack location and depth in stepped Euler-Bernoulli beam carrying concentrated masses. In order to estimate crack location and depth in the beam, the proposed algorithm utilizes the variation of the difference between the natural frequencies of cracked and intact systems versus single mass location along the beam span. The assumed mode method is used to derive the mathematical model for the system under investigation.

In this paper, the crack in free-free beam is simulated by an equivalent axial spring, connecting the two segments of the beam. Analysis of this approximate model results in algebraic equation, which relates the natural frequencies of the beam and crack location. The relationship between the natural frequencies, crack location, and crack size has also been developed.

\section{Identification of crack location in free-free beam}

The physical model that will be considered in this work is a free-free uniform Euler-Bernoulli beam, as shown in Fig. 1. The length of the beam is $L$ and it has a crack at a distance $L_{1}$ from the left end. The beam has constant cross-section area $A$ and geometric moment of inertia $I$. Its material properties, Young's modulus ( $E$ ) and mass density $(\rho)$ are also constant. The equation of motion of Euler-Bernoulli beam for axial vibration is given by,

$\frac{\partial^{2} u}{\partial x^{2}}=\frac{1}{c^{2}} \frac{\partial^{2} u}{\partial t^{2}}$

where, $c^{2}=\frac{E}{\rho}$

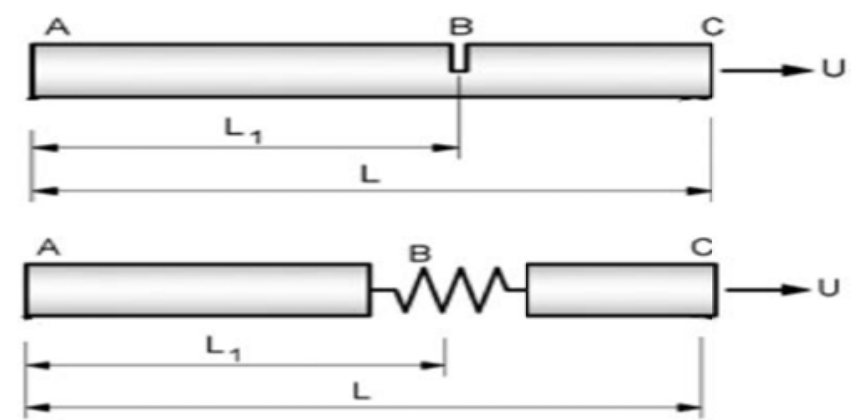

Fig. 1. Model of cracked free-free beam

This equation does not hold near the crack, due to abrupt change of the cross section. The beam can be treated as two uniform beams, connected by an axial spring at the crack location. The Eq. (1) is then valid for each segment of the beam separately, with the appropriate boundary condition. The left segment of the beam will be designated by subscript 1 and the right one by 2 . The end points are designated by A and C, and the crack section by B. The beam Eq. (1) is solved by standard method of separation of variables, hence for two beam segments we get,

$$
\begin{aligned}
& U_{1}(x)=a_{1} \sin \left(\frac{\omega}{c} x\right)+a_{2} \cos \left(\frac{\omega}{c} x\right), \\
& U_{2}(x)=a_{3} \sin \left(\frac{\omega}{c} x\right)+a_{4} \cos \left(\frac{\omega}{c} x\right),
\end{aligned}
$$


where the origin $x$ for both segments is at the end. The coefficients $a_{i}$ can be found by substituting this solution in the boundary conditions. The boundary conditions for a free-free beam are as follows. For the free vibrations of the beam, there is no external excitation and consequently no axial force at the ends.

$U_{1 A}^{\prime}=U_{2 C}^{\prime}=0$,

and the continuity conditions at the crack position the displacement, moments, and shear forces are.

$U_{1 B}^{\prime}=U_{2 B}^{\prime}$

With the nondimensional crack section flexibility denoted by $\Theta$, the angular displacement between the two beam segments can be related to the force at this section by,

$U_{2 B}-U_{1 B}=\Theta_{A} L U_{2 B}^{\prime}$.

Substituting above boundary conditions in Eqs. (2-3) and equating the system determinant to zero, algebraic equations for the natural frequencies of the cracked beam are obtained, where, $\Theta_{A}$ is the non-dimensional axial flexibility $=\left(E I / K_{x} L\right), \beta$ is the non-dimensional frequency parameter $=\lambda L$, and $e$ is non-dimensional crack location $=\left(L_{1}-L / 2\right) /(L / 2)$.

The linear set of equation reduces to a single trigonometric equation,

$4 \sin \beta \sinh \beta+\beta \Theta_{A}[\sinh \beta(\cos \beta-\cos e \beta)+\sin \beta(\cosh \beta-\cosh e \beta)]=0$

The above equation is obtained by simplifying and solving the matrix using MUPAD platform of MATLAB.

For a constant crack location, a partial differentiation with respect to $\Theta_{A}$ leads yields,

$4(\cos \beta \sinh \beta+\sin \beta \cosh \beta)\left(\partial \beta / \partial \Theta_{A}\right)+\beta[\sinh \beta(\cos \beta-\cos e \beta)+\sin \beta(\cosh \beta-\cosh e \beta)]+$

$\Theta_{A} \frac{\partial}{\partial \beta}\{\beta \sinh \beta(\cos \beta-\cos e \beta)+\sin \beta(\cosh \beta-\cosh e \beta)\} \frac{\partial \beta}{\partial \Theta_{A}}=0$

If it is assumed that the original beam was uncracked, with negligible equivalent flexibility, the nominal values of $\Theta_{A}$ in the Eq. (8) become zero. When $\Theta_{A}=0$ and $\beta=n \pi$, we get

$4 \cos \left(\partial \beta / \partial \Theta_{A}\right)+\beta(\cos \beta-\cos e \beta)=0$.

The Eq. (9) is now written as a difference equation,

$4 \cos (\beta)\left(\frac{\Delta \beta}{\beta}\right)=(\cos e \beta-\cos \beta) \Delta \Theta_{A}$.

By definition of nondimensional frequency parameter, it is given that $2 \frac{\Delta \beta}{\beta}=\frac{\Delta f}{f}$. Therefore Eq. (10) can be rewritten for the $\mathrm{i}^{\text {th }}$ mode as,

$2 \cos \left(\beta_{i}\right)\left(\frac{\Delta f_{i}}{f_{i}}\right)=\left(\cos e \beta_{i}-\cos \beta_{i}\right) \Delta \Theta_{A}$

For the first natural mode $\beta_{1}=\pi$, therefore, above equation yields, 
$2\left(\frac{\Delta f_{1}}{f_{1}}\right)=-(1+\cos 2 e \pi) \Delta \Theta_{A}$

and for the second mode $\beta_{2}=2 \pi$, therefore, above equation yields,

$2\left(\frac{\Delta f_{2}}{f_{2}}\right)=-(1-\cos 2 e \pi) \Delta \Theta_{A}$.

Dividing Eq. (13) by Eq. (12) and simplifying,

$e=\frac{1}{\pi} \cos ^{-1}\left(1-\frac{\left(\Delta f_{2} / f_{2}\right) /\left(\Delta f_{1} / f_{1}\right)}{2}\right)$,

where, $\Delta f_{n}$ in Eq. (14) suggests that the ratio of the relative vibrations of two modes depends solely on the location of the crack and is independent of crack geometry or beam properties, no information is required even about the configuration of crack, that is whether it is one-sided, two-sided, or starts on the side faces of the beam.

\section{Identification of crack size for free-free beam}

Consider a typical beam structure that has been damaged by a discrete crack. Based on the consideration of the characteristic equations of the physical model shown in Fig. 1, The eigenfrequency change ratio $\Delta f_{n} / f_{n}$ and the dimensionless stiffness $K$ is given as,

$$
\frac{\Delta f_{n}}{f_{n}}=2 g_{n}(x) \frac{1}{K}
$$

where,

$$
K=K_{x} L / E A
$$

$x$ is the non-dimensional crack location $=L_{1} / L$ or $\frac{(e+1)}{2}, \Delta f_{n}=f_{n}-\overline{f_{n}}$ is the difference between the natural frequencies of the cracked and the uncracked beam.

The $g_{n}(x)$ function for a free-free beam can be evaluated as:

$g_{n}(x)=\frac{1}{4} \frac{\left[\varphi_{n}^{\prime \prime}(x)\right]^{2}}{\int_{0}^{1}\left[\varphi_{n}^{\prime \prime}(x)\right]^{2} d x}$

From elementary beam theory, the mode shapes of beams with typical homogeneous boundary conditions can be easily calculated. For free-free beam, the mode shape is $\varphi_{n}=\sin (n \pi x)$. Therefore for a free-free beam, the relationship between the changes in eigenfrequencies and the crack location and stiffness of crack based on Eqs. (15-17) is expressed as:

$\frac{\Delta f_{n}}{f_{n}}=\sin ^{2}(n \pi x) \frac{E A}{K_{x} L}$. 
The spring stiffness $K_{x}$ in the vicinity of the cracked section of a beam having width $b$, height $h$ , and a crack depth $a$ can be determined from the crack strain energy function, given by Rizos and Aspragathos (1990),

$$
K_{x}=\frac{E A}{(5.346 h) f(a / h)} .
$$

Putting this value in Eq. (18):

$$
\frac{\Delta f_{n}}{f_{n}}=\sin ^{2}(n \pi x) \frac{5.346 h . f(a / h)}{L},
$$

therefore,

$$
\frac{\Delta f_{n}}{f_{n}}=5.346 \sin ^{2}\left(n \pi \frac{(e+1)}{2}\right) \frac{h \cdot f(a / h)}{L},
$$

where,

$$
\begin{aligned}
& f(a / h)=1.8624(a / h)^{2}-3.95(a / h)^{3}+16.375(a / h)^{4}-37.226(a / h)^{5}+78.81(a / h)^{6}-126.9(a / h)^{7}+172(a / h)^{8} \\
& -143.97(a / h)^{9}+66.56(a / h)^{10}
\end{aligned}
$$

Putting this value in Eq. (21) and neglecting higher order values, the equation becomes,

$$
\left(\frac{a}{h}\right)^{2}=\frac{\Delta f_{n} / f_{n}}{9.9563 \sin ^{2}\left[n \pi \frac{(e+1)}{2}\right] \frac{h}{L}} \text {. }
$$

Using Eq. (22), the crack depth ratio ( $a / h$ ) can be found out if the natural frequencies of the cracked and uncracked beam and the crack location are known.

\section{Analysis of cracked beam by ANSYS FEM package}

In the method of crack detection in beam by vibration signatures, it is very essential to know the changes in natural frequency because of the crack. In case of intact beam, natural frequencies are determined using standard formulas, but for cracked beam it is very difficult to determine natural frequencies theoretically. Hence, the frequencies of cracked free-free beam are determined either experimentally or by finite element method and these obtained frequencies are fed to analytical model to assess a crack location and crack depth ratio. The natural frequencies of the beam were calculated by ANSYS FEM package. An Aluminium beam of length $L=300 \mathrm{~mm}$, height $h=25 \mathrm{~mm}$, breadth $b=10 \mathrm{~mm}$, Young's Modulus $E=0.65 * 10^{11} \mathrm{~N} / \mathrm{m}^{2}$, and mass density $\rho=2700 \mathrm{Kg} / \mathrm{m}^{3}$ was chosen. The two natural frequencies are calculated for uncracked and cracked beam. The results of the ANSYS FEM computation and crack location and crack size evaluated by Eq. (14) and Eq. (22) are given in Table 1.

\section{Table 1}

Results of aluminium beam with crack depth ratio $a / h=0.1$ by ANSYS

\begin{tabular}{lccccc}
\hline Case & Uncracked & Crack 1 & Crack 2 & Crack 3 & Crack4 \\
\hline Actual : crack location $(e)$ & - & 0.2 & 0.4 & 0.6 & 0.8 \\
\hline Frequencies & & & & & \\
$\mathrm{f}_{1}(\mathrm{~Hz})$ & 8176 & 8124 & 8150 & 8167 & 8171 \\
$\mathrm{f}_{2}(\mathrm{~Hz})$ & 16343 & 16300 & 16271 & 16296 & 16308 \\
\hline Predicted: crack location $(e)$ from Eq. $(14)$ & - & 0.2085 & 0.0400 & 0.5993 & 0.7708 \\
Crack depth ratio $(a / h)$ from Eq. $(22)$ & - & 0.0924 & 0.0765 & 0.0617 & 0.0767 \\
\hline
\end{tabular}




\section{Analysis of Cracked Beam Experimentally}

The experiments are done on free-free beam having a crack. The tests are carried out for different crack locations and for different crack sizes. The experimental set up consists of the test instruments shown in Fig. 2. The test specimens have length $300 \mathrm{~mm}$ and a rectangular cross section which is $10 \mathrm{~mm}$ in breadth and $25 \mathrm{~mm}$ in depth. Both ends of the beam are wound with two strings and suspended freely with frame. This was done in an attempt to simulate the free-free boundary condition. First un-cracked beam is tested for its natural frequency followed by the cracked one. The beams, which are tested, are made up of aluminium, with the data for them as listed in the section analysis of cracked beam by ANSYS FEM package. Now the experimental data obtained, that is, natural frequencies of un-cracked and cracked beams are fed to Eq. (14) and Eq. (22) to identify the crack location and the crack size. The results obtained by experimental analysis for identification of crack location and crack size are evaluated by Eq. (14) and Eq. (22) and are given in Table 2.

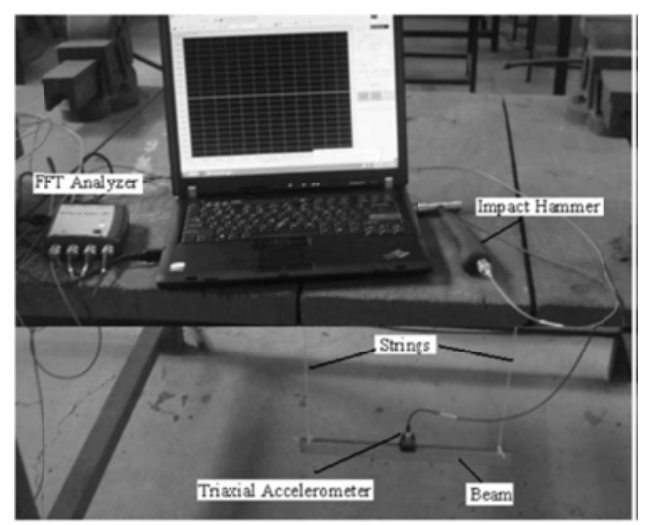

Fig. 2. Experimental setup of free-free beam

Table 2. Actual, theoretical and experimentally predicted crack location $(e)$ and crack size $(a / h)$

\begin{tabular}{lcccc}
\hline Case & $e$ & $E$ & $a / h$ (for $\underline{\underline{e}}=0.2)$ & $a / h$ (for $e=0.4$ ) \\
\hline Actual & 0.2 & 0.4 & 0.3 & 0.4 \\
Theoretical(ANSYS) & 0.2085 & 0.38 & 0.38 & 0.47 \\
Experimental & 0.1894 & 0.33 & 0.36 & 0.45 \\
\hline
\end{tabular}

\section{Results}

The various results obtained by numerical (ANSYS) and experimental analysis for identification of crack location and crack size are shown in Fig. 3 in the form of graph.
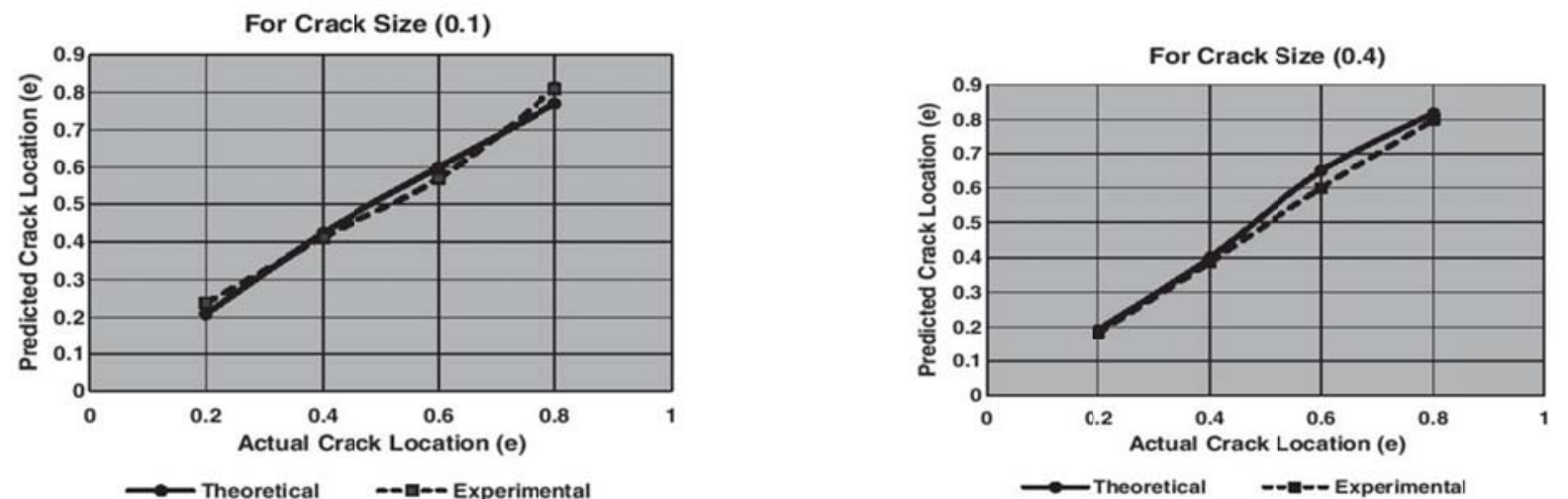

Fig. 3. Graph relating the theoretical and experimental crack location $(e)$ to crack size $(a / h)$ 


\section{Conclusions}

In this paper, a method for detection of crack from measurement of natural frequencies of cracked free-free beam for axial vibration is developed. For identification of crack location and crack depth ratio, it was shown that data on the variation of the first two natural frequencies is sufficient. The crack is simulated by an equivalent axial spring, connecting the two segments of the beam. Analysis of this approximate model results in algebraic equations, which relate the natural frequencies of beam and crack location. These expressions are applied to studying the inverse problem, that is, identification of crack location from frequency measurements. For crack size an integrated approach is used, which gives a relation between frequencies' changes, crack location, and crack size in the beam. The error in prediction of crack location and crack size by theoretical and experimental analysis is less than $16 \%$. The proposed method is confirmed by comparing it with results of ANSYS FEM results. The proposed method is found to be both simple and accurate.

\section{References}

Adams, R.D., \& Cawley, P.A. (1978). Vibration technique for non-destructively assessing the integrating ofstructures. Journal of Mechanical Engineering Science, 20(2), 93-100.

Christides, S., \& Barr, A.D.S. (1984). One dimensional theory of cracked Bernoulli-Euler beams. International Journal of Mechanical Science, 26(11/12), 639-648.

Douka, E., \& Hadjileontiadis, L.J. (2005). Time-frequency analysis of the free vibration response of a beam with abreathing crack. NDT\&E International, 38(1), 3-10.

Ishak, S.I., Liu, G.R., \& Lim S.P. (2000). Study on characterization of horizontal cracks in isotropic beams. Journal of Sound and Vibration, 238(4), 661-671.

Kam, T.Y., \& Lee, T.Y. (1991). Detection of cracks in structures using model test data. Engineering Fracture Mechanics, 42(2), 381-387.

Liang, R.Y., Choy, F.K., \& Hu, J. (1992). A quantitative NDE technique for assessing damage in the beamstructures. Journal of Engineering Mechanics ASCE, 118(7), 1468-1487.

Liang, Y., \& Hu, J. (1993). An integrated approach to detection of cracks using vibration characteristics. Journal of Franklin Institute, 330(5), 841-853.

Loya, J.A., \& Rubio, L. (2006). Natural frequencies for bending vibrations of Timoshenko cracked beams. Journal of Sound and Vibration, 290, 640-653.

Matveev, V.V., \& Bovsunovsky, A.P. (2002). Vibration-based diagnostics of fatigue damage of beam-like structures. Journal of Sound and Vibration, 249(1), 23-40.

Narkis, Y. (1994). Identification of crack location in vibrating simply supported beams. Journal of Sound and Vibration, 172(4), 549-558.

Ostachowicz, W.M., \& Krawczuk, M. (1991). Analysis of the effect of cracks on the natural frequencies ofcantilever beam. Journal of Sound and Vibration, 150, 191-201.

Ren, W.X., \& De Roeck, G. (2002). Structural damage identification using modal data. I: Simulation Verification. Journal of Structural Engineering, 128(1), 87-95.

Rizos, P.F., \& Aspragathos, N. (1990). Identification of crack location and magnitude in a cantilever beam from the vibration modes. Journal of Sound and Vibration, 138(3), 381-338.

Al-Said, S. M. (2008). Crack detection in stepped beam carrying slowly moving mass. Journal of Vibration and Control, 14(12), 1903-1920.

Stubbs, N., \& Broome, T.H. (1990). Nondestructive construction error detection in large space structures. American Institute of Aeronautics and Astronautics Journal, 28, 146-152.

Zheng, D.Y., \& Kessissoglou, N.J. (2004). Free vibration analysis of a cracked beam by finite element method. Journal of Sound and Vibration, 273, 457-475. 